\title{
La libertad de la persona en la Ley Fundamental de Alemania según la jurisprudencia del Tribunal Constitucional Federal ${ }^{*}$
}

\author{
Dieter Lorenz $z^{* *}$ \\ Recibido: 15 de mayo de 2016 • Aprobado: 11 de junio de 2016
}

\section{Resumen}

Tras las garantías jurídicas de la Edad Media y de la Edad Moderna temprana (Carta Magna; Ley de Habeas Corpus), la Ley Fundamental alemana garantiza jurídica y -materialmente la libertad de la persona como derecho fundamental (art.2, inciso 2, frase 2). Esta garantía se complementa con la garantía judicial para adoptar privaciones de libertad (art. 104, incisos 2, 3). Su contenido actual de protección ha sido moldeado, en esencia, por la jurisprudencia del Tribunal Constitucional Federal que ha destacado el peso especial de la libertad frente a intromisiones preventivas (detención preventiva, custodia de seguridad) y ha exigido un aseguramiento complementario por medidas procesales. Así mismo la libertad se ha proyectado de manera variable respecto de distintas situaciones de los extranjeros (asilo, expulsión, entrega). También el Tribunal Constitucional Federal ha reconocido y fortalecido el derecho de autodeterminación de los enfermos mentales en relación con las limitaciones a la libertad y el tratamiento médico (libertad de permanecer enfermo). La Corte Europea de Derechos Humanos y el Tribunal Constitucional Federal Alemán han impulsado que las medidas de custodia de seguridad hayan sido seriamente reformadas (separación de la ejecución penal, resocialización).

"El presente artículo es resultado de la producción académica generada por el convenio suscrito entre la Universidad Santo Tomas (Sede Bogotá) y la Universidad de Konstanz - Alemania. El proyecto de investigación al que se adscribe el presente artículo es: "Die Herausforderungen der Verfassung und Verwaltung gegen den Frieden und die öffentliche Sicherheit”. DOI: http://dx.doi.org/10.15332/ s1900-0448.2016.0045.02

" Profesor emérito de la Universidad Konstanz, doctor honoris causa - Universidad Santo Tomás, ex-vicerrector de la Universidad Konstanz, ex-presidente del Senado de la Universidad Konstanz, exdecano de la Facultad de Derecho. El Autor agradece la traducción a Catalina Ibáñez Gutiérrez, L.L.M. y doctorante en la Universidad Konstanz, y a Diana Sanabria Ramírez, abogada y estudiante L.L.M. en la Universidad Konstanz. Correo Electrónico: dieter.Lorenz@uni-konstanz.de 
Palabras clave: cadena perpetua, Convención Europea de Derechos Humanos, custodia de seguridad, detención preventiva, resocialización.

\title{
The FREEDOM OF THE INDiVidual IN THE Basic LAW OF Germany according to the case laW of the Federal Constitutional Court
}

\begin{abstract}
Following the legal safeguards created during the Middle Ages and early modern period (Magna Charta Libertatum, Habeas Corpus Act), the German constitution guarantees individuals' freedom as a substantive fundamental right (art. 2 par. 2 s. 2). This is supplemented by a formal protection in the form of judges reserving the right to intervene in case of any deprivation of liberty (art. 104 par. 2, 3). The legal scope of this right has been substantially developed in the case law of the Federal Constitutional Court of Germany (Bundesverfassungsgericht, BVerfG). Here, judges have emphasized the special weight of personal freedom in cases of infringement (for example, detention awaiting trial or preventive detention) and demanded a complementary procedural protection of this fundamental right. The legal stance on the personal freedom of foreigners (in the cases of asylum, deportation or extradition) is evaluated differently. Mentally ill persons' right to self-determination in relation to restrictions of freedom and medical treatment (freedom to have a disease) has been acknowledged and strengthened. As initiated by the European Court of Human Rights (ECHR) and the BVerfG, preventative detention has been newly regulated amid the separation of execution of sentence and the emphasis on rehabilitation.
\end{abstract}

Keywords: Custodial sentence, European Convention on Human Rights, life imprisonment, preventive detention, resocialization. 


\section{A liberdade da pessoa na Lei Fundamental da Alemanha SEgundo a JURisprudência do Tribunal Constitucional FEDERAL}

\section{Resumo}

Após as garantias jurídicas da Idade Media e da Idade Moderna (Carta Magna; Lei de Habeas Corpus), a Lei Fundamental alemã garante jurídica e materialmente a liberdade da pessoa como direito fundamental (art. 2, inciso 2, frase 2). Esta garantia complementa-se com a garantia judicial para adotar privações da liberdade (art. 104, incisos 2,3 ). Seu conteúdo atual de proteção tem sido moldado, em essência, pela jurisprudência do Tribunal Constitucional Federal que tem destacado a importância especial da liberdade perante as intromissões preventivas (detenção preventiva, custódia de segurança) e tem exigido um asseguramento complementário por medidas processuais. Também a liberdade tem se projetado de maneira variável sobre distintas situações dos estrangeiros (asilo, expulsão, entrega) Também o Tribunal Constitucional Federal tem reconhecido e fortalecido o direito de autodeterminação dos doentes mentais em relação com as limitações da liberdade e do tratamento médico (liberdade de permanecer doente). A Corte Europeia de Direitos Humanos e o Tribunal Constitucional Federal Alemão têm impulsado que as medidas de custódia de segurança tenham sido seriamente reformadas (separação da execução penal, ressocialização)

Palavras-chave: Prisão perpétua, Convenção Europeia dos Direitos Humanos, custódia de segurança, detenção preventiva, ressocialização.

\section{Introducción}

En el orden constitucional de la República Federal de Alemania le corresponde una sobresaliente y determinante importancia al Tribunal Constitucional. Esto resulta de su papel de guardián de la Constitución con amplias competencias de control frente a los demás poderes estatales, es decir, el legislativo, ejecutivo y judicial, así como el efecto vinculante de sus decisiones para la totalidad del poder público. Desde esta base adquiere una influencia determinante en el orden jurídico. Ya que no solo puede corregir cualquier sentencia u otras formas de jurisprudencia, 
sino sobre todo, objetar leyes por ser inconstitucionales o exigir su promulgación como constitucionalmente convenientes. ${ }^{1}$

E1 Tribunal Constitucional Federal como órgano judicial (art. 92 LF) está vinculado a la ley y al derecho y, por tanto, a la Ley Fundamental (art. 20 inciso 3 LF). Como órgano constitucional, el Tribunal está en la misma categoría que los demás órganos federales - el Parlamento Federal (Bundestag), el Consejo Federal (Bundesrat), el Gobierno Federal (Bundesregierung) - sin embargo, determina por sí mismo decisiva y definitivamente el contenido jurídico de las normas constitucionales. De esta forma sobre todo son desenvueltos y perfeccionados los derechos fundamentales en la interpretación y aplicación constitucional, así que el contenido y el alcance de las garantías resultan, después de todo, de la jurisprudencia del Tribunal Constitucional Federal. También el derecho fundamental reconocido en el art. 2 inciso 2 LF ("La libertad de la persona es inviolable") fue moldeado en su importancia actual como muralla de contención para la libertad existencial humana por una jurisprudencia del Tribunal Constitucional Federal cualitativa y cuantitativamente amplia. Por ende vale la pena examinar de cerca algunas líneas de desarrollo notables de esta jurisprudencia.

El rasgo antropológico determinante del carácter del hombre es su libertad: "Todas las personas nacen libres" (art. 13 inciso $1 \mathrm{CN}$ Col.), es decir, ellas son por naturaleza autónomas y en su comportamiento no se someten a ninguna voluntad ajena. Esto se aplica en especial a la libertad de movimiento físico, la libre decisión de ir donde uno quiera y no ser detenido de manera forzada en un determinado lugar. Esta libertad en sentido estricto, fundada en el Derecho natural, ${ }^{2}$ determina - junto a la vida y la integridad física - la existencia humana física básica y es una condición elemental de una existencia humana. ${ }^{3}$ Así que quien está privado de la libertad, no puede auto-determinarse, sino que está a merced de la disposición del titular soberano u otro mandatario y es dependiente de su ayuda asistencial para la conservación de su vida y su salud.

${ }^{1}$ Véase Badura (2003), Staatsrecht, p. 708; Hillgruber/Goos (2003), Verfassungsprozessrecht, p. 5 ss., 19.

${ }^{2}$ Merten (2011), en: HGR, tomo IV, número marginal 6; Di Fabio (2009), en: Maunz/Dürig, Grundgesetz, Art. 2 II, número marginal 7.

${ }^{3}$ Tribunal Constitucional Federal (TCF), colección de decisiones (BVerfGE) 10, 302 (322); 53, 152 (158); 130, 372 (388); Di Fabio (2009), op. cit., número marginal 16; Gusy (2011), en: HGR, tomo IV, número marginal 6. 
En consecuencia, la garantía de la libertad de la persona se encuentra en todas las constituciones modernas, por lo menos de carácter occidental ${ }^{4}$ - pero, por ejemplo, también en China o en Egipto - y hoy puede ser considerada como bien común general en el derecho constitucional. Sin embargo, la libertad personal es aún uno de los bienes jurídicos más amenazados. Con ello pertenece a los derechos garantizados más antiguos. Ya en las garantías jurídicas de la Edad Media y de los principios de la Edad Moderna, las primeras garantías de la libertad personal se encuentran en forma de promesas del soberano; así - para nombrar solo a las más famosas - en la Carta Magna de las libertades (1215) y en la Ley de Habeas Corpus (1679). ${ }^{5}$ Sin embargo, éstas no contienen ninguna garantía material expresa de la libertad como tal, como ahora suele ser el caso de otros derechos fundamentales - la libertad de culto, la libertad de expresión y de prensa, la protección del patrimonio. La libertad de la persona, más que otorgada, es presupuesto de estado natural y por tanto solo es protegida "de manera negativa" frente a una privación injustificada, así que ésta requiere una decisión judicial previa. No obstante, este requerimiento procedural se basa materialmente en el reconocimiento de la libertad como bien jurídico digno de protección. Por ende, aquella garantía formal puede ser vista como precursora del derecho fundamental de la libertad de la persona. ${ }^{6}$

La garantía formal de la tradicional protección del Habeas Corpus se encuentra materializada también en la Ley Fundamental (art. 104 inciso 2 y 3 LF) y tiene relación inseparable con la garantía material de la libertad (art. 2 inciso 2 LF). ${ }^{7}$ A consecuencia de ello, únicamente el juez debe decidir sobre la admisibilidad y duración de una privación de la libertad. Si alguien es detenido por la policía o arrestado bajo sospecha de un delito, la decisión judicial de un juez debe ser solicitada y presentada de inmediato, a más tardar al término del día siguiente. Se trata de un plazo máximo tras el cual el afectado debe ser puesto en libertad, sin importar las razones objetivas de peso que justificarían que la custodia policial continuara. Por otra parte, exige la protección del derecho fundamental, que la intromisión a la libertad sin autorización judicial sea limitada en el tiempo al máximo necesario (principio de la proporcionalidad, ver más adelante). Permanecer en espera hasta

${ }^{4}$ Véase Lorenz (2015), en: Bonner Kommentar, Art. 2 número marginal 935.

${ }^{5}$ Véase Stern (2006), p. 121; Riedel (1980), en: EuGRZ p. 192.

${ }^{6}$ Wittreck (2009), en: HStR, tomo VII, p. 284; Riedel (1980), en: EuGRZ p. 192

${ }^{7}$ BVerfGE 10, 302 (322); 105, 239 (247); Jarass/Pieroth (2014), Grundgesetz, Art. 2 número marginal 110. 
el final del plazo máximo constitucional para la obtención de la decisión judicial, sin que aquello sea objetivamente necesario, es una práctica inconstitucional y que ha sido criticada en varias ocasiones por el Tribunal Constitucional Federal.

\section{La protección de la libertad personal en la Ley Fundamental}

\section{Situación normativa}

Teniendo en cuenta el trasfondo histórico de derecho natural descrito, el artículo 2 inciso 2 frase 2 LF determina a continuación de las garantías del derecho a la vida y a la integridad física lo siguiente: "La libertad de la persona es inviolable". Este derecho fundamental en virtud de la relación normativa sistemática no protege la libertad general al libre desarrollo de la personalidad, que está garantizada por separado en el art. 2, inciso $1 \mathrm{LF}$ (cf. también Art. $16 \mathrm{CN} \mathrm{Col}$ ), sino únicamente la libertad de movimiento corporal. ${ }^{8}$ Ésta goza como bien jurídico absoluto de una protección frente cualquier perjuicio real y por lo tanto no está limitada a formas de manifestación tradicionales.

Sin embargo, el modelo histórico de la protección Habeas Corpus se refiere a la defensa de intromisiones estatales, causadas por detenciones injustificadas de tipo penal. El Tribunal Constitucional Federal da por sentado, empero, que el fin de la garantía jurídico-material es la integridad del bien jurídico de la libertad. Como consecuencia su protección constitucional no puede restringirse principalmente al contexto penal y con eso dejar de lado otras formas de manifestación de privación de la libertad legalmente admitidas. Así sucede respecto del internamiento de un enfermo mental en una clínica psiquiátrica en razón de una orden de derecho público de la autoridad. ${ }^{9}$ Del mismo modo, se considera el internamiento mediante un tutor en representación del enfermo. ${ }^{10}$ Esto último se realiza, a decir verdad, sobre la base del derecho civil, y por lo tanto únicamente en la relación entre particulares, que,

${ }^{8}$ BVerfGE 22, 21 (26); 96, 10 (21); Schulze-Fielitz (2013), en: Dreier (ed.), Grundgesetz, Art. 2 II número marginal 98.

${ }^{9}$ BVerfGE 128, 282 (311 ss.); 130, 372 (390).

${ }^{10}$ BVerfGE 10, 302 (323); Corte Suprema Federal (BGH), BGHZ 166, 141 (148); Heidebach (2014), p. 74 ss. 
de acuerdo con el derecho constitucional alemán, no están vinculados directamente a los derechos fundamentales (art. 1 inciso 3 LF). Sin embargo, el tutor obtiene la facultad de internamiento privativo de la libertad del enfermo, solo por medio de una autorización legal. Esta autorización legal está atribuida al Estado y, por tanto, también puede ser ejercida por un particular solamente en virtud de una admisión judicial. ${ }^{11}$

\section{La importancia del Tribunal Constitucional Federal para la protección de la libertad}

Por lo demás el Tribunal Constitucional Federal también ha llamado la atención sobre la dimensión constitucional que tienen los principios tradicionales, existentes en un Estado de derecho en caso de ingerencias administrativas y obligatorios en la justicia penal.

Estos principios tuvieron que introducirse particularmente en las clínicas psiquiátricas, las cuales a menudo se orientaban de acuerdo con las costumbres de práctica antiguas y autoritarias. Pero también en el ámbito de la justicia penal, hasta la fecha, el Tribunal Constitucional Federal ha tenido que exigir el cumplimiento de los requirimientos constitucionales de acuerdo con su jurisprudencia permanente y vinculante.

En 1985 el Tribunal Constitucional Federal revocó ${ }^{12}$ varias decisiones de los tribunales superiores, la última del año 1980, en las cuales se había rehusado suspender la privación de la libertad en un establecimiento psiquiátrico por más de once años y conceder libertad condicional. Se apoyaron en un dictamen médico de seis años de antigüedad y no tuvieron en cuenta que la causa del internamiento fue un hurto bajo la influencia del alcohol, el cual estaba penalizado solo con nueve meses de prisión.

En un tiempo más reciente un caso ha atraído la atención. ${ }^{13}$ En dicho caso el acusado fue absuelto de los cargos por lesiones personales y otros delitos, a causa de su inculpabilidad, e internado en un hospital psiquiátrico. Cinco años después fue decretada la continuación del internamiento, pues la peligrosidad fue ratificada por medio de un dictamen médico, contradictorio en sì mismo, el cual fue aceptado por el juzgado sin haber sido revisado. El fondo del caso parece escandaloso: el punto

\footnotetext{
${ }^{11}$ BVerfGE 10, 297 (322).

${ }^{12}$ BVerfGE 70, 297.

${ }^{13}$ BVerfG, decisión del 26 de agosto de 2013, en: Neue Juristische Wochenschrift (NJW) 2013, p. 3228.
} 
de partida fue una pelea matrimonial, en la cual el esposo había agredido a su esposa, culpándola de haber sido parte de una grave evasión de impuesto en el banco, donde ella trabajaba. Esta aseveración fue considerada como una alucinación, pero resultó ser cierta de acuerdo a un dictamen del banco en el año 2008. No obstante, el condenado siguió permaneciendo en custodia del Estado. Solo después de críticas públicas e intensas a la Ministra de Justicia en el Parlamento y en los medios de comunicación, en el año 2013, la Fiscalía interpuso recurso de revisión y el afectado fue puesto en libertad. Posteriormente el Tribunal Constitucional Federal se pronunció sobre su acción de tutela y afirmó que los juzgados penales "no han cumplido con las exigencias constitucionales, establecidas para una justificación de la continuación de un internamiento en un hospital psiquiátrico, ya excepcionalmente largo" (es decir, cinco años). ${ }^{14}$

E1 Tribunal Constitucional Federal está proporcionando protección y atención pública del derechos fundamental de la libertad personal, no solo en los casos cotidianos sencillos de lesiones del derecho en la organización de justicia. Más bien, su jurisprudencia presupone también impulsos importantes para el desarrollo y la remodelación del derecho, en lo referente a la privación estatal de la libertad, sobre todo en las áreas de la justicia criminal y del internamiento psiquiátrico, tema a lo que me voy a referir más adelante.

\section{La restricción de la libertad personal}

Con la garantía fundamental de la libertad de la persona la Constitución reconoce el estatus de libertad de los individuos. La libertad tiene su fundamentación y origen en el derecho natural, y por lo tanto no es solo otorgada jurídicamente, sino meramente reconocida. Si se partiera de este estatus material, la privación de la libertad se vería puesta como punto central. Como ya se ha mostrado, el ámbito de la protección del derecho fundamental se define también históricamente a partir de la defensa de dicha intromisión. ${ }^{15}$

${ }^{14}$ Cf. Walter (2014), en: GA p. 316; Streng (2014), en: ZG p. 24

${ }^{15}$ Véase BVerfGE 94, 166 (198); Merten (2011), op. cit., HGR, número marginal 10; Di Fabio (2009), op. cit., Art. 2 II número marginal 3, 22. 


\section{La intromisión en la libertad}

Desde sus primeras decisiones hasta hoy, el Tribunal Constitucional Federal ha resaltado el valor particular de la libertad personal, que se traduce tanto en una garantía expresa como inviolable. ${ }^{16}$ La libertad - a diferencia de la dignidad humana (Art. 1 inciso $1 \mathrm{LF}$ ) - no es, por supuesto intangible. Ella es sin embargo, un bien jurídico tan alto que "solo puede ser restringido por razones de gran peso" ${ }^{17}$ Tales razones pueden ser la necesidad de una persecución penal efectiva, así como la protección preventiva contra cualquier violación de derechos, principalmente mediante la comisión de delitos. En algunos supuestos pero de manera restrictiva también pueden ser internados los enfermos mentales por su propia seguridad en un establecimiento psiquiátrico. ${ }^{18}$

\section{Límites de la privación de la libertad}

En el presente análisis interesa en primer lugar la privación de la libertad y los limites para su restricción. La privación de libertad es la "forma más grave de la restricción de la libertad" y se presenta, cuando se retira la libertad de movimiento corporal innata en todas las direcciones" ${ }^{\prime 1}$, en particular, cuando alguien en contra o sin su voluntad es recluido en un lugar cerrado. Una privación de la libertad es únicamente admisible "cuando se impone de manera forzosa ante el preponderante interés del bien común" 20 . Para lo cual se requiere una prueba estricta de la proporcionalidad $^{21}$.

La intromisión debe ser adecuada y necesaria para alcanzar el objetivo de un fin legítimo. Así, por ejemplo, la custodia policial de una persona para determinar su identidad es inadmisible, si ésta se puede comprobar por medio de sus documentos de identidad presentes.

Particularmente hay que ponderar la urgencia del interés general con la pérdida de la libertad. En este sentido, la pretensión de la libertad obtiene un peso elevado,

\footnotetext{
${ }^{16}$ BVerfGE 10, 302 (322); 35, 185 (190); 109, 190 (239).

${ }^{17}$ BVerfGE 22, 180 (219); 45, 187 (223); 130, 372 (388).

${ }^{18}$ BVerfGE 58, 208 (224); 128, 282 (305); Wittreck (2009), op. cit., HStR, p. 298.

${ }^{19}$ BVerfGE 10, 302 (323); 105, 239 (248).

${ }^{20}$ BVerfGE 53, 152 (158); 58, 208 (225).

${ }^{21}$ BVerfGE 19, 342 (347); 29, 312 (316); 70, 297 (311); 130, 372 (389).
} 
cuando la intromisión sirve para la protección preventiva, como en los casos de la prisión provisional, la custodia de seguridad y la negación de la suspensión condicional de la pena a libertad, debido al riesgo de una nueva comisión de delitos. En tales casos la intromisión no puede ser apoyada por hechos probados, sino que se basa en el mero pronóstico de situaciones futuras esperadas. La privación de la libertad sobre una base tan incierta requiere por tanto, una justificación particular. ${ }^{22}$

En general, la intromisión admisible en el derecho fundamental de libertad depende en alto grado de las estimaciones y ponderaciones, y no es por ello claramente delimitada. En consecuencia gana importancia elevada la protección procesal-jurídica del derecho fundamental. ${ }^{23}$ Ésta ha encontrado su expresión más importante ya en la Constitución (art. 104, inciso 2-4 LF) en forma de reserva judicial para las privaciones de libertad. Además existen requisitos para la Administración y para los juzgados, que deben asegurar la legalidad de la intromisión en la libertad. Estos requisitos incluyen sobre todo una aclaración de los hechos adecuada y, si es necesario, con la ayuda de un perito independiente, además elaborar una fundamentación sustancial de la decisión, de manera que se posibilite un examen jurídico-constitucional ${ }^{24}$ - se trata de mandatos, que son ya inmanentes en las actividades judiciales.

En la privación preventiva de la libertad con fines de aseguramiento (prisión preventiva), el mandato de aceleración del proceso tiene central importancia para restringir la privación de libertad a la mayor brevedad posible. ${ }^{25}$ Esto está dirigido a todos los organismos responsables de la privación de libertad y requiere del juez, por ejemplo, una rápida dirección de los debates procesales (no solo una audiencia judicial por semana), ${ }^{26}$ de la administración de justicia la producción inmediata del protocolo y la notificación de la sentencia, así como del legislador la asignación de personal suficiente en el caso de sobrecarga del juzgado ${ }^{27}$. En caso de violación al requisito de aceleración del proceso, la medida privativa de libertad puede llegar a ser inconstitucional y, por ello, puede ser abolida.

\footnotetext{
${ }^{22}$ BVerfGE 58, 208 (224); 130, 372 (389); Dessecker (2004), p. 205.

${ }^{23}$ Véase BVerfGE 65, 1 (52); 113, 29 (57); Heidebach (2014), op. cit., p. 90 ss.

${ }^{24}$ BVerfGE 58, 208 (222); 70, 297 (308); 109, 133 (162).

${ }^{25}$ BVerfGE 20, 45 (50); 46, 194.

${ }^{26}$ BVerfG, sentencia del 17 de enero de 2013, en: Strafverteidiger (StV) 2013, p. 640.

${ }^{27}$ BVerfGE 36, 264 (274).
} 


\section{Ámbito de protección y la intromisión}

La determinación clara, y solo fácticamente consolidada, del significado y alcance de lo que es una privación de la libertad se centra en la salvaguardia de la libertad natural real, y delimita el contenido mínimo de protección del derecho fundamental. Esto posiblemente se puede extender a ciertas situaciones de privación de libertad sin detención física directa, como se discute por ejemplo en el caso del grillete electrónico (par. 68b inciso 1 no. 12 Código Penal). ${ }^{28}$ Se excluye, sin embargo, una restricción por criterios funcionales, mediante los cuales la existencia de una intromisión en el derecho fundamental se ponga en duda, a pesar de que el afectado no puede alejarse. A tal efecto, me gustaría referirme a la llamada custodia de tránsito en el aeropuerto de extranjeros ilegales (que ingresan a un país) y la internación de un enfermo para protegerlo contra sí mismo.

a. Como en todos los Estados, para ingresar a la República Federal de Alemania los extranjeros requieren una autorización (un llamado permiso de residencia, parágrafo 4 AufenthG - Ley de residencia), por ejemplo una visa. A falta de esta, el extranjero es rechazado en la frontera (parágrafo 15 AufenthG), para evitar que ingrese. Sin embargo, desde el punto de vista jurídico, una entrada no es realizada, si al extranjero se le permitió provisionalmente cruzar la frontera, mientras que permanezca bajo el control de las autoridades de la frontera, hasta que su autorización de ingreso sea aclarada, o su rechazo sea preparado (parágrafo 13 inciso 2 AufenthG). Si el rechazo no puede ser llevado a cabo directamente por impedimentos reales del paso fronterizo, el extranjero se encuentra detenido. Esto sin duda es una privación de la libertad, que debe ser dispuesta por un juez (parágrafo 15 inciso 5 AufenthG).

Sin embargo existe una situación fáctica y jurídica particular, si el extranjero ha llegado por vía aérea al territorio alemán, pero por la ausencia del permiso no puede ingresar y por lo tanto fue rechazado. En este caso, él no ha ingresado jurídicamente, a pesar de que está realmente presente en el territorio federal, y por lo tanto también está protegido por la Constitución. Pero ya que él no está autorizado para la estancia, debe ser transportado de vuelta. La aclaración de las condiciones y circunstancias de la partida pueden tardar un largo tiempo. Durante este intervalo de tiempo el extranjero permanece bajo vigilancia en la zona de tránsito del aeropuerto

${ }^{28}$ Cf. Merten (2011), op. cit., HGR, número marginal 11 
o en un alojamiento adecuado (parágrafo 15 inciso 6 AufenthG). Comparable, bajo ciertas condiciones es la situación de los solicitantes de asilo antes del fallo sobre su solicitud de asilo (parágrafo 18a AsylVerfG).

Aunque los afectados son retenidos en un espacio reducido durante este tiempo, para la opinión mayoritaria, y respaldada por el criterio del Tribunal Constitucional Federal, en este caso no hay privación de la libertad. ${ }^{29} \mathrm{El}$ Tribunal establece que el derecho fundamental a la libertad de la persona (art. 2, inciso 2, frase $2 \mathrm{LF}$ ) protege dentro del sistema jurídico vigente el movimiento físico real, que no es "la facultad de permanecer por doquier e indefinidamente, y de poder moverse por todas partes". La frontera del Estado es un obstáculo para la libre circulación, establecido legalmente. Dado que el Estado en el ejercicio de su soberanía está facultado para establecer los criterios en caso del cruce de su frontera, mediante el impedimento de acceso al territorio, no es afectada la garantía fundamental de la libertad del individuo. ${ }^{30}$

Este argumento supone que la estancia forzada en el aeropuerto es prácticamente requisito imprescindible para el impedimento del ingreso, pero mezcla este objetivo con los medios aplicados para la restricción de la libertad. El vínculo funcional entre las dos circunstancias no compensa su separación jurídica. En el presente se trata de la libertad de movimiento corporal. La ficción de que, debido al rechazo, el ingreso no fue exitoso, no cambia nada la presencia real del extranjero en el territorio de la República Federal de Alemania, ni mucho menos que el extranjero detenido en el área de tránsito - como debe reconocer el mismo Tribunal Constitucional Federal - realmente está restringido en su libertad de movimiento. ${ }^{31}$ Esta medida, que claramente es atribuible al poder del Estado alemán y que, por lo tanto está sujeta a los derechos fundamentales (art. 1 inciso 3 LF), constituye una intromisión en el derecho a la libertad (art. 2, inciso 2 LF). ${ }^{32}$ En este asunto la Corte Europea de Derechos Humanos (CEDH) coincide en que en la detención de extranjeros en la zona internacional constituye una restricción de la libertad, que tras una duración excesiva se condensa en una privación de la libertad. ${ }^{33}$ Del mismo modo la Corte

${ }^{29}$ BVerfGE 94, 166 (198); Stern/Sachs (2006), op. cit., Staatsrecht, tomo IV/1, p. 1091; Jarass/ Pieroth (2014), op. cit., Art. 2 número marginal 115.

${ }^{30}$ BVerfGE 94, 166 (198).

${ }^{31}$ BVerfGE 94, 166 (199).

${ }^{32}$ Igual Wittreck (2009), op. cit., HStR, p. 296.

${ }^{33} \mathrm{CEDH}$, dec. 10 de diciembre de 2006, no. 13178/03. 
Suprema Federal aplica las precauciones de protección en la estancia forzada en el aeropuerto, que deben observarse en el caso de la detención. ${ }^{34}$

De esto resultan consecuencias importantes. Como intromisión en un derecho fundamental, la restricción de la libertad jurídico-material debe ser proporcionada y, en particular, no debe superar el tiempo mínimo necesario. De ello se desprende una obligación destinada a acelerar la realización del proceso oficial (principio de aceleración $)^{35}$. Formal y legalmente, se requiere una orden judicial siempre que haya una privación de libertad. Sin embargo, tal orden judicial está prescrita legalmente solo después de los treinta (30) días siguientes a la llegada (par. 15 inciso 6 AufenthG). El hecho de que el legislador no haya regulado una decisión judicial previa a la privacioón de la libertad dentro de este lapso, no significa que se pueda renunciar a dicho requisito constitucional.

Algunos autores también niegan la intromisión, bajo el punto de vista del consentimiento, debido a que los extranjeros podrían, sin más, terminar con la privación de la libertad a través de la salida (del país) voluntaria. ${ }^{36}$ Sin embargo, esta posibilidad por regla general no podría ser realizable y, en caso de solicitantes de asilo, quedaría prácticamente excluida.

No obstante, la existente intromisión a la libertad a causa de la detención del extranjero no lesiona necesariamente el derecho fundamental del art. 2 inciso 2 LF. Más bien hay que diferenciar. De hecho, la estancia forzada en el aeropuerto sirve para la comprobación de la residencia, y, por lo tanto para el permiso de ingreso. Esta es una condición necesaria para decidir, si puede, o no, entrar al territorio, y a la vez es interés del mismo detenido. Durante el tiempo necesario de la comprobación solo se presenta como restricción de la libertad. La cual puede ser llevada a cabo sobre la base legal sin una orden judicial. No obstante el legislador puede establecer el período de tiempo necesario después del cual la restricción de la libertad pasará a ser una privación de libertad que requiere una orden judicial. Sin embargo, la renuncia legal de esta forma a una duración de 30 días, parece como desproporcionada y por tanto incumple los requisitos constitucionales.

b. La cualidad de la intromisión de una medida privativa de libertad también está en duda si ésta sirve para la protección de una lesión a sí mismo. Regularmente,

\footnotetext{
${ }^{34}$ BGH, decisión del 30 de junio de 2011, en: Neue Zeitschrift für Verwaltungsrecht (NVwZ-RR) 2011, p. 875.

${ }^{35}$ BVerfGE 64, 46 (65); 46, 194.

${ }^{36}$ Gusy (2011), op. cit., HGR, número marginal 13.
} 
las intromisiones a los derechos fundamentes se legitiman con la protección de otros bienes jurídicos o ámbitos de vida. ${ }^{37}$

En general se discute mucho si el menoscabo de los bienes jurídicos constitucionalmente protegidos, a través de medidas estatales destinadas a proteger a la misma persona constituye una injerencia y si el Estado está facultado para actuar así. ${ }^{38}$ También se plantea esta cuestión respecto del derecho fundamental de la libertad de la persona. En primer plano se encuentra aquí el internamiento, legalmente previsto, de las personas con enfermedad mental en un establecimiento psiquiátrico con el fin de protegerlos de un peligro de sí mismos a la vida o la salud. Este instrumento de protección de bienes jurídicos se lleva a cabo por ejemplo después de un intento de suicidio. Esto puede ser visto como una expresión de un trastorno mental, como resultado de que - al menos en el momento de la comisión - el libre ejercicio de la voluntad se excluye y se consideran necesarias medidas de protección. El detenido será de ese modo privado de su libertad, empero - visto objetivamente - en su propio interés: para mantener su vida y su salud como fundamentos de su existencia física.

Pese a esta finalidad, aun existe la intromisión en la libertad de la persona y no se compensa por la ventaja para el afectado, objetivamente brindada. La situación aquí es parecida a la lesión en el cuerpo por una intervención médica. Debido a su propósito de la recuperación, no el menoscabo de la integridad física, antiguamente por una opinión dominante no fue considerado como intromisión. Hoy en día, ni siquiera aquí la existencia de una intromisión está puesta en duda. ${ }^{39}$

En consecuencia, actualmente no hay duda de que el internamiento en un establecimiento psiquiátrico significa una privación de la libertad que necesita la legitimación ante el derecho fundamental de la libertad de la persona (art. 2, inciso $2 \mathrm{LF}$ ). ${ }^{40}$ Originalmente la intromisión fue justificada con base en la tarea de la policía del mantenimiento de la seguridad pública, que incluye la protección de la vida y la salud, frente a cualquier peligro (también por lado del titular del derecho fundamental). Entretanto, se ha reconocido que se trata en el fondo de la protección de los bienes jurídicos subjetivos de la persona afectada, y proporciona

\footnotetext{
${ }^{37}$ Hesse (1995), p. 142.

${ }^{38}$ BVerfGE 58, 208 (225); Kirste (2011), en:JZ p. 811; Hillgruber (1992), Der Schutz des Menschen gegen sich selbst.

${ }^{39}$ BVerfGE 128, 282 (302).

${ }^{40}$ BVerfGE 58, 208 (225); 128, 282 (304).
} 
la justificación de la privación de libertad principalmente en el cuidado de bienestar social para los individuos que lo necesitan. ${ }^{41}$

Sin embargo, frente a este objetivo paternalista, el Tribunal Constitucional Federal estableció límites claros de la autonomía individual al juzgar el tratamiento forzoso oficial de los pacientes en los establecimientos psiquiátricos. ${ }^{42}$ El objetivo de la internación no es solo el aseguramiento externo real para prevenir futuros actos de infracción, sino, en particular, el tratamiento de la enfermedad mental. Es admisible como injerencia en la integridad física únicamente con el consentimiento. El derecho de autodeterminación sobre su propio cuerpo se arraiga en la intangible dignidad humana (art. 1, inciso $1 \mathrm{LF}$ ) lo que vale sin distinción para un enfermo mental. A ésto le incumbe por lo tanto también determinar sobre la pérdida de su libertad personal, con el fin de realizar un tratamiento médico.

Por lo tanto el internamiento en contra de la voluntad natural de un enfermo mental solo puede ser considerado, si éste, debido a su enfermedad, no está dispuesto a reconocer la necesidad de un tratamiento hospitalario y no es responsable para decidir por sí mismo. ${ }^{43}$ Para ello, son necesarias exigencias estrictas para salvaguardar el derecho de libertad personal, particularmente valioso. Por lo tanto es condición del internamiento forzoso que la capacidad de discernimiento esté claramente ausente y haya un peligro considerable de daño grave. En cuanto el enfermo mental tenga capacidad de decisión, entonces sigue aun teniendo la "libertad de la enfermedad"44; a este respecto tendría que decidir el enfermo sobre sí mismo, y no una razón objetiva de los médicos o del Estado sobre él.

\section{La privación de la libertad en el derecho penal}

\section{Los problemas básicos}

Además del internamiento en un establecimiento psiquiátrico por razones cuidadosas, la privación de libertad como consecuencia de un delito se presenta como

${ }^{41}$ BVerfGE 10, 302 (326); 58, 208 (224).

${ }^{42}$ BVerfGE 128, 282 (301).

${ }^{43}$ BVerfGE 58, 208 (225); 128, 282 (304); BGH, en: Neue Juristische Wochenschrift (NJW) 2012, p. 3234

${ }^{44}$ BVerfGE 58, 208 (226). 
el segundo ámbito importante en la práctica, en el que es anulada la libertad. En este contexto, la intención protectora del Tribunal Constitucional Federal de los derechos fundamentales es particularmente evidente en favor de la libertad personal.

E1 Tribunal Constitucional destaca la pretensión principal y persistente del particular a la libertad frente a la privación de libertad y sus modalidades. Este derecho individual - por ejemplo, en la prisión preventiva - tiene que ser enfrentado permanentemente a las restricciones de la libertad, necesarias desde el punto de vista de la persecución penal. ${ }^{45}$ De aquí se desprende, por ejemplo, la exigencia de una revisión regular acerca de si la detención es aún necesaria o puede ser sustituida por otras medidas (garantía de seguridad en riesgo de fuga) y, si en caso de una duración prolongada, aún guarda una adecuada proporción con el castigo esperado.

Así mismo e independientemente de ello, un límite de tiempo para la detención preventiva surge tanto de la prohibición de exceso (principio de la proporcionalidad, derivado del art. 20, inciso 3 LF) así como del derecho, derivado de la legislación europea, de ser juzgado dentro de un plazo razonable (art. 5, inciso 3 del Convenio Europeo de Derechos Humanos - CEDH); en principio, doce o también ocho años de prisión preventiva, incluso en delitos graves, es un período demasiado largo. ${ }^{46}$

La privación de la libertad penal persigue dos objetivos. Por un lado, sirve en forma de pena privativa de la libertad como sanción por el injusto, cometido culpablemente (principio de la culpabilidad), y por el otro lado, debe impedir la comisión de nuevos delitos por medio de la custodia; aquí el propósito de seguridad determina la duración de la privación de la libertad. ${ }^{47}$ En contraste con los sistemas monistas, en los que la pena de prisión uniformemente cumple con las funciones sancionatorias y las funciones de la seguridad, en el derecho penal alemán son diferenciadas estrictamente la pena de prisión y las medidas de mejoramiento y de seguridad. Como consecuencia de ello, junto con la pena de prisión puede ser además ordenado el internamiento en la custodia de seguridad, si se presume el peligro de que el condenado cometa en el futuro delitos graves. El autor no es condenado, debido a la incapacidad de culpabilidad, sino que es internado en un hospital psiquiátrico, ya que a causa de su estado resulta ser peligroso para la comunidad.

Cualquier tipo de detención penal significa para el afectado un rompimiento de su vida normal, que lo aparta en gran parte de las relaciones sociales. Por lo

\footnotetext{
${ }^{45}$ BVerfGE 19, 342 (347); 20, 45 (49); 53, 152 (158).

${ }^{46}$ BVerfGE 53, 152.

${ }^{47}$ BVerfGE 45, 187 (253); 109, 133 (173).
} 
tanto, la dignidad humana, así como los principios del Estado social y de derecho, requieren una configuración de la privación de libertad de una manera que ésta permita al prisionero a su reinserción en la sociedad y una vida libre de crimen. Por lo tanto, el objetivo de la resocialización ${ }^{48}$ es pauta necesaria de cada privación estatal de libertad prolongada.

A continuación deben ser atendidas la pena de prisión y la custodia de seguridad.

\section{La pena de prisión}

La pena de prisión es una sanción por una conducta antijurídica y culpable. Para ella tiene validez el principio de culpabilidad, arraigado en la idea de la justicia y la dignidad humana; de este modo la pena impuesta no puede sobrepasar la medida de la culpabilidad. La gravedad del delito y de la culpabilidad del infractor deben estar en una relación adecuada respecto de la pena. ${ }^{49}$

Existe un problema particular, relacionado con la pena de cadena perpetua. Luego de la abolición de la pena de muerte (art. 102 LF), la cadena perpetua es la pena máxima por delitos capitales, como el asesinato y el genocidio, y no ha sido cuestionada por la Constitución, a diferencia del Art. 34 de la Constitución colombiana. Como máxima amenaza de pena, es vista como conveniente por la opinión mayoritaria también actualmente. Sin embargo, si la cadena perpetua se cumple efectivamente, se excluye desde el principio y de forma permanente al individuo de la sociedad, y su existencia social como persona es negada. Esto lesiona la dignidad humana. (art. 1, inciso $1 \mathrm{LF}$ ).

Por lo tanto su protección requiere que "el condenado tenga la posibilidad concreta y principalmente realizable de poder obtener de nuevo la libertad en algún momento posterior" ${ }^{50}$ Se debe examinar si se dan las condiciones para una suspensión condicional de la pena privativa de la libertad en relación con los objetivos de la pena - compensación de la culpa y la seguridad - de acuerdo con un periodo admisible, que es establecido por la ley a los quince (15) años. Un periodo más largo puede ser necesario, si el tribunal, al dictar la sentencia, ha encontrado una gravedad particular de culpabilidad. ${ }^{51}$ Ya que la absoluta amenaza penal de cadena

\footnotetext{
${ }^{48}$ BVerfGE 98, 169 (199); 116, 69 (85); 128, 326 (378).

${ }^{49}$ BVerfGE 6, 389 (439); 45, 187 (260); 95, 96 (140); 133, 168 (197).

${ }^{50}$ BVerfGE 45, 187 (245); 117, 71 (95).

${ }^{51}$ BVerfGE 86, 288 (315); Kett-Straub (2011), Die lebenslange Freiheitsstrafe.
} 
perpetua no admite la diferenciación de la graduación de la pena, debe ser tenido en cuenta el mayor o menor grado de culpabilidad en la decisión sobre la puesta en libertad anticipada. Sin embargo, siguiendo el enfoque del Tribunal Constitucional Federal, la sola gravedad de la culpabilidad no justifica ninguna privación de por vida de libertad como una consecuencia del hecho. En cambio, para la protección de la comunidad frente a futuras y esperadas lesiones a bienes jurídicos y debido a la existencia de peligro de reincidencia, es admisible con la dignidad humana que la pena dictada (por el juez) se continúe ejecutando. ${ }^{52}$ Aquí sin embargo, el derecho a la libertad individual exige observancia, ya que, entre más dure la privación de la libertad, este (derecho) se vuelve más fuerte. Una vez más, las garantías procesales adquieren importancia, por lo que los hechos exactos deberán establecerse con la inserción de peritos, así como la exposición precisa de los motivos por los que persiste la peligrosidad del delincuente.

\section{La custodia de seguridad (internamiento preventivo de seguridad)}

La pena de prisión, entendida como sanción de un hecho antijurídico y culpable, de acuerdo con el principio de culpabilidad, solo puede ser impuesta en la medida de la culpabilidad imputada al autor. Para la protección adicional de la comunidad frente a nuevos hechos antijurídicos significativos, se aplican privaciones de libertad en forma de medidas de seguridad. Esta protección es garantizada, por un lado, mediante la seguridad directa frente al peligro emanado por el detenido. Por otro lado, se debe lograr por medio de medidas terapéuticas una mejora en términos de una reducción de la energía criminal del condenado, para así evitar la amenaza para la comunidad. ${ }^{53}$ Como requisito de una privación de la libertad, que respeta la dignidad humana, la resocialización también sirve a los intereses del detenido.

La custodia de seguridad es fundamentalmente distinta de la pena de libertad por su finalidad exclusiva de protección. Se produce cuando existe una condena, mientras que el internamiento en un hospital psiquiátrico requiere que el delincuente no haya sido condenado, debido a su incapacidad de culpabilidad. Por ello no puede producirse una situación de concurrencia con la pena privativa de libertad.

\footnotetext{
${ }^{52}$ BVerfGE 109, 133 (156); 117, 71 (96).

${ }^{53}$ BVerfGE 130, 372 (390); Stree/Kinzig (2014), en: Schönke/Schröder (ed.), Strafgesetzbuch, § 63 número marginal 1.
} 
En la consideración de la custodia de seguridad existe una fundamental discordia entre el Tribunal Constitucional Federal (TCF) y la Corte Europea de Derechos Humanos (CEDH), que llevó a un cambio profundo en la ejecución de la medida en Alemania. El detonante fue una nueva ley, por medio de la cual se derogó el periodo de duración máximo de diez (10) años de la custodia de seguridad hasta allí existente, válida incluso para los autores que fueron condenados bajo el antiguo régimen de custodia de seguridad de no más de diez (10) años. Su internamiento podía ser entonces extendido de manera retroactiva, si se consideraba que había riesgo de que cometieran delitos graves con daño mental o físico grave para la víctima. ${ }^{54}$

Para el Tribunal Constitucional Federal, la custodia de seguridad sirve exclusivamente al aseguramiento de la comunidad y por ende no se considera como una pena en el sentido de la Constitución. Por ello, no está sujeta a las respectivas garantías constitucionales y del derecho europeo (Art. 5, 7 Convencion europea de Derechos humanos - ConvEDH). De este modo, no alcanza a la custodia de seguridad la estricta prohibición de retroactividad ni el principio ne bis in idem (art. 103, inciso 2 y 3 LF). En consecuencia, la constitucionalidad de las medidas de custodia de seguridad solo se evalúa, de acuerdo con los principios de proporcionalidad y de confianza legítima. Así, si hay amenaza de que se pueden cometer delitos por el condenado, las referidas garantías no se aplican y no obstaculizan la extensión posterior del internamiento. ${ }^{55}$

En contraste, la Corte europea rechazó principalmente la distinción entre las sanciones represivas (pena de prisión) y la seguridad preventiva (custodia de seguridad). La Corte está basándose en el art. 5, inciso 1, frase 2 ConvEDH, de acuerdo con el cual - según aquí de importancia - una persona puede ser privada de su libertad solo en virtud de una condena judicial con determinación de culpabilidad (lit. a), o si se trata de las personas con enfermedad mental, o bien, adictas a las drogas o al alcohol (lit. e) ${ }^{56}$ Entonces la posterior ampliación de la custodia de seguridad no solo infringió el art. $5 \mathrm{ConvEDH}$, sino también la prohibición de la pena sobre la base de una ley retroactiva de conformidad con el art. 7 de la Convención Europea. Lo mismo se aplica a una orden posterior de la custodia de

\footnotetext{
${ }^{54}$ Gesetz zur Bekämpfung von Sexualdelikten del 26 de enero de 1998, BGB1 I (Boletín oficial) p. 160.

${ }^{55}$ BVerfGE 109, 133 (174).

${ }^{56} \mathrm{CEDH}$, sentencia del 17 de diciembre de 2009, en: Neue Juristische Wochenschrift 2010, p. 2495; Renzikowski (2013), en: NJW p. 1639.
} 
seguridad para los autores, que solo fueron condenados a pena de prisión, y que se habían mostrado como altamente peligrosos durante el período de detención. ${ }^{57}$

De esta jurisprudencia antagónica, una especie de “choque de trenes", se genera un dilema teórico jurídico. En virtud del Art. 46. inciso 1 ConfEDH, las decisiones de la Corte Europea son vinculantes para los tribunales nacionales y, por lo tanto, también para el Tribunal Constitucional alemán. Sin embargo, la Convención de los Derechos Humanos tiene en Alemania solo un rango de ley y, por lo tanto, en la jerarquía jurídica es inferior a la Constitución. Desde el punto de vista jurídicomaterial el conflicto normativo entre la Convención Europea de Derechos Humanos y la Ley Fundamental se debe resolver en favor de la constitución nacional. Sin embargo, la Ley Fundamental se caracteriza por una orientación amigable al derecho internacional público, que se expresa en el preámbulo y en los artículos. 23, 24 y 25. Por lo tanto, en general se supone que las disposiciones de la Convención de Derechos Humanos se superponen, en relación con su interpretación por el juzgado competente, a la interpretación constitucional. ${ }^{58}$ En consecuencia, dada una colisión de normas de hecho la Corte Europea dispone del contenido material de la Ley Fundamental. El Tribunal Constitucional Federal, en su decisión de principio de 4 de mayo de $2011^{59}$, ha tomado en cuenta esta situación jurídica y con ello ha iniciado una reorganización de la custodia de seguridad, que en su repercusión real no ha sido llevada a cabo hasta hoy.

La privación de la libertad por custodia de seguridad no se aplica a los condenados en respuesta a su lesión culpable de la ley, sino como una medida preventiva frente a su amenaza de peligrosidad. En consecuencia, esta medida preventiva, debe fundamentarse en el hecho que dió motivo para la internación y ha de estar basada en un pronóstico de que se pueden acometer nuevos actos antijurídicos, por los cuales actualmente no se hace responsable el condenado y por los cuales no puede ser acusado. Con la privación de la libertad en el interés de la comunidad el afectado es cargado con un sacrificio especial, que representa una intervención muy grave en su libertad. ${ }^{60}$ Sin embargo, esta intervención se justifica en la necesidad urgente de seguridad de la comunidad ante la alta probabilidad de futuras violaciones de derecho

${ }^{57} \mathrm{CEDH}$, sentencias del 17 de diciembre de 2009; del 13 de enero de 2011 (17792/07 y 6587/04); del 7 de junio de $2012(61827 / 09)$.

${ }^{58}$ BVerfGE 74, 358 (370); 111, 307 (327); Grabenwarter (2012), en: EuGRZ p. 507.

${ }^{59}$ BVerfGE 128, 326

${ }^{60}$ BVerfGE 128, 326 (374); 130, 372 (390). 
en relación con el grave indicio del hecho ocasional, que se atribuye al afectado. ${ }^{61}$ Sin embargo, esta intervención es compatible con el derecho fundamental de la libertad solo si es proporcional al peligro y se evitan las desventajas, que van más allá de la privación de la libertad puramente externa.

Así pues, la custodia de seguridad se debe diferenciar sustancialmente de la detención penal, en tanto, que ésta solo puede ser ejecutada dentro de un lugar diferente de una cárcel (orden de separación). ${ }^{62}$ Esto contradice la anterior aplicación jurídica de la custodia de seguridad en los pabellones especiales de las cárceles y ha levado a la declaración de inconstitucionalidad de las normas pertinentes. Como consecuencia fue necesaria la adopción de nuevas leyes en la Federación y en los Estados federados ante el 31 de mayo de 2013. Mas bien era necesaria la creación real de nuevas instalaciones, que posibilitaran diferentes equipamientos y un estilo de vida diferente al de los centros penitenciarios. Su instalación no solo ha encontrado problemas financieros, sino también la - bastante comprensible - protesta en la población. Además, el requisito mencionado de resocialización ${ }^{63}$ es de particular importancia.

Además de la transformación fundamental de la custodia de seguridad, sigue siendo necesario que la comunidad sea protegida frente a autores de delitos que representen un peligro significativo de cometer delitos graves, o delitos violentos o sexuales. Teniendo en cuenta la jurisprudencia de la Corte Europea de Derechos Humanos en virtud del art. 5 ConvEDH, la adopción de este tipo de medidas solo es posible en el caso de los enfermos mentales y requiere, dada la gravedad de la interferencia retroactiva, un riguroso examen de proporcionalidad. Así, el legislador ha creado en la Ley de Internación Terapéutica del 22 de diciembre de 2010, y con ello surge una tercera forma de internamiento además de la custodia de seguridad para autores con responsabilidad penal completa y el internamiento en el hospital psiquiátrico para los autores con incapacidad de culpabilidad. ${ }^{64}$ La nueva ley considera autores penalmente responsables, de los cuales emana un alto grado de peligro (de comisión) de delitos violentos, o de delitos sexuales graves, con base en su trastorno mental. Esto se debe a la personalidad perturbada del delincuente, pero que no tiene, sin embargo, importancia médica. Se supone que de acuerdo

\footnotetext{
${ }^{61}$ BVerfGE 109, 190 (220); Streng (2013), en: StV p. 236 ss.

${ }^{62}$ BVerfGE 128, 326 (376); 109, 133 (166); 134, 33 (62); Streng (2011) en: JZ p. 831.

${ }^{63}$ BVerfGE 109, 133(150); 130, 372 (390); 131, 268 (282).

${ }^{64}$ BVerfGE 134, 33 (77 ss.).
} 
con el dogma de la voluntad libre, la capacidad de acción y autodeterminación no está afectada, por lo tanto la responsabilidad penal no puede anularse.

En resumen con todo esto se demuestra la gran importancia que tiene el Tribunal Constitucional Federal para el desarrollo y la consolidación del derecho fundamental de la libertad de la persona. Como no ocurre con casi ningún otro derecho fundamental, el Tribunal ha objetado en numerosas decisiones una y otra vez los errores y descuidos de los tribunales especializados, y se ha asegurado de concientizar el valor creciente de la libertad a las autoridades responsables por su privación. Así, ha asegurado no solo la protección efectiva de este bien legal de alto nivel, sino también ha hecho más clara en general su función esencial para la protección del derecho fundamental.

No es casualidad que el Tribunal Constitucional Federal alemán disfrute de una alta estima entre la población - según una encuesta de opinión la Ley Fundamental cuenta con una aprobación del $91 \%$, mientras que el Tribunal Constitucional cuenta con un $86 \%$ de aprobación, aún más que el Presidente Federal con el $75 \%$ y el Gobierno Federal (50 \%) y que, muy por debajo, la Comisión Europea (29\%) y los partidos políticos (23\%).

\section{Conclusiones}

Tras las garantías jurídicas de la Edad Media y de la Edad Moderna temprana (carta magna; Ley de habeas corpus), la Ley Fundamental alemana garantiza jurídica y materialmente la libertad de la persona como derecho fundamental (art. 2, inciso 2, frase 2). Esta garantía se complementa con la garantía judicial para adoptar privaciones de libertad (art. 104, incisos 2, 3). Su contenido actual de protección ha sido moldeado, en esencia, por la jurisprudencia del Tribunal Constitucional Federal, que ha destacado el peso especial de la libertad frente a intervenciones preventivas (detención preventiva, custodia de seguridad) y ha exigido un aseguramiento complementario por medidas procesales. También la libertad se ha proyectado de manera variable respecto de distintas situaciones de los extranjeros (asilo, expulsión, entrega). Así mismo, el Tribunal Constitucional Federal ha reconocido y fortalecido el derecho de autodeterminación de los enfermos mentales en relación con las limitaciones a la libertad y el tratamiento médico (libertad de permanecer enfermo). La Corte Europea de Derechos Humanos y el Tribunal Constitucional Federal alemán han impulsado que las medidas de 
custodia de seguridad hayan sido seriamente reformadas (separación de la ejecución penal, resocialización).

\section{Referencias}

Badura, P. (2003). Staatsrecht (3.a ed). München: Verlag C.H. Beck.

Dessecker, A. (2004). Gefährlichkeit und Verbältnismäßigkeit. Berlin: Duncker \& Humblot.

Di Fabio, U. (2009). Art. 2 II. En Maunz/Dürig (ed.), Grundgesetz, Kommentar. München: Verlag C.H. Beck.

Grabenwarter, Chr. (2012). Die deutsche Sicherungsverwahrung als Treffpunkt grundrechtlicher Parallelwelten. Europäische Grundrechte Zeitschrift (EuGRZ), 507, 509-510.

Gusy, Chr. (2011) § 93. Freiheit der Person. En Merten/Papier (ed.), Handbuch der Grundrechte (Manual de derechos fundamentales - HGR) (Tomo IV). Heidelberg: C.F. Müller.

Heidebach, M. (2014). Grundrechtsschutz durch Verfahren bei gerichtlicher Freiheitsentziehung. Berlín: Duncker \& Humblot.

Hesse, K. (1995). Grundzüge des Verfassungsrechts der Bundesrepublik Deutschland (20.a ed.). Heidelberg: C.F. Müller.

Hillgruber, Chr. (1992). Der Schutz des Menschen gegen sich selbst. München: F. Vahlen.

Hillgruber, Chr., \& Goos, Chr. (2003). Verfassungsprozessrecht. Heidelberg: C.F. Müller.

Jarass, H., \& Pieroth, B. (2014). Grundgesetz, Kommentar (13.a ed.). München: Verlag C.H. Beck.

Kett-Straub, G. (2011). Die lebenslange Freiheitsstrafe. Tübingen: Mohr Siebeck.

Kirste, St. (2011). Harter und weicher Rechtspaternalismus. Juristenzeitung (JZ), 17, 805-814.

Lorenz, D. (2015). Art. 2 II. En Bonner Kommentar zum Grundgesetz. Heidelberg: C.F. Müller.

Merten, D. (2011). § 95. Bewegungsfreiheit. En Merten/Papier (ed.), Handbuch der Grundrechte (HGR) (Tomo IV). Heidelberg: C.F. Müller.

Renzikowski, J. (2013). Abstand Halten. Neue Juristische Wochenschrift (NJW), 23, 1638-1644.

Riedel, E. (1980). Die Habeas Corpus-Akte. Europäische Grundrechte Zeitschrift (EuGRZ), 182-200.

Schönke/Schröder. (2014). Strafgesetzbuch (Código Penal) (29.a ed.). München: F. Vahlen.

Schulze-Fielitz. (2013). Art. 2 II. En Dreier (ed.), Grundgesetz, Kommentar (3.a ed.). München: Verlag C.H. Beck.

Stern, K. (2006). Das Staatsrecht der Bundesrepublik Deutschland (tomo IV/1). München: Verlag C.H. Beck. 
Streng, F. (2011). Die Zukunft der Sicherungsverwahrung. Juristenzeitung (JZ), 17, 827-835. Streng, F. (2013). Zur Legitimation der Sicherungsverwahrung. Strafverteidiger (StV), 4, 236, 243.

Streng, F. (2014). Problembereiche und Reformperspektiven der Unterbringung in einem psychiatrischen Krankenhaus. Zeitschrift für Gesetzgebung (ZG), 29(1), 24-42.

Walter, T. (2014). Die Freiheit der Person und die Psychiatrie. Goltdammer's Archiv für Strafrecht (GA), 161(6), 316-332.

Wittreck, F. (2009). § 151. Freiheit der Person. En Isensee/Kirchhof (ed.), Handbuch des Staatsrechts (Manual del derecho constitucional-HStR) (3.a ed.) (Tomo VII). Heidelberg: C.F. Müller. 